\title{
Religious Beliefs and Their Relevance for Treatment Adherence in Mental Illness: A Review
}

\author{
Paweł Zagożdżon * and Magdalena Wrotkowska \\ Department of Hygiene and Epidemiology, Medical University of Gdansk, 80-211 Gdansk, Poland; \\ m.wrotka@gumed.edu.pl \\ * Correspondence: pzagoz@gumed.edu.pl; Tel.: +48-58-349-1928
}

Received: 6 July 2017; Accepted: 8 August 2017; Published: 14 August 2017

\begin{abstract}
Approximately 50\% of patients do not adhere to medical therapy. Religious and spiritual factors may play an important role in determining medication compliance in mental illness. The aim of this paper is to review published evidence documenting a relationship between religion/spirituality $(\mathrm{R} / \mathrm{S})$ and treatment adherence in mental illness, in particular in schizophrenia, depression and substance abuse. This review summarizes, categorizes and defines the role of religious beliefs as a factor improving medication compliance in mental illness. Randomized controlled trials and observational studies were eligible for the review if they were published in December 2015 or earlier, analyzed the effects of religious beliefs or spirituality on medication compliance, or adherence to other therapeutic interventions in mental illness. The vast majority of published studies analyzed the effects of religion on medication compliance in schizophrenia and addiction. In schizophrenia patients, religious beliefs turned out to be a predictor of worse treatment adherence. However, spiritual orientation was shown to play an important role in the recovery from addiction, and to improve adherence in patients with this condition. Furthermore, better treatment adherence was observed in more religious patients diagnosed with depression. While religious beliefs and spirituality may represent an important source of hope and meaning, they often interfere with treatment adherence. Therefore, psychiatrists should consider religious and spiritual beliefs of their patients, and verify if and to what extent they improve their medication compliance.
\end{abstract}

Keywords: religion; treatment adherence; mental illness

\section{Introduction}

While lack of medication adherence may be observed in essentially all chronic conditions, it is particularly challenging in mental disorders. The latter are typically associated with social isolation, stigmatization, comorbid substance abuse, lack of insight, depression and cognitive impairment. Moreover, treatment adherence may be affected by both positive and negative symptoms of the mental illness itself.

The key therapeutic objectives in mental illness is to adequately control its symptoms and to ensure treatment adherence of the patient. Treatment adherence improves mental health and facilitates resolution of the underlying illness. Adherence is defined as the extent to which the patient's behaviors, such as medication taking, diet and lifestyle modification comply with doctor's recommendations (Haynes et al. 1977). Religion beliefs may influence medication compliance in mental illness to a large extent. If a mental illness is supposed to result from or may be associated with spiritual problems, pharmacotherapy may not be enough. Some patients may believe that medication taking or medical advice seeking reflect the lack of their faith in God's ability to heal the disease without a medical intervention. However, if religious beliefs promote self-care for somatic and mental health as a manifestation of good overall status, they may also exert a beneficial effect on medication 
compliance (O Sarri et al. 2005). Some persons may consider treatment adherence as a disobedience to religious doctrines. Such opinions may be shared by patients, their relatives and/or members of local communities, influencing their attitude to prescribed treatment.

Published evidence suggests that lack of treatment adherence is a more serious issue in psychiatry than in general medicine. In a review paper analyzing treatment adherence in psychiatric and somatic disorders throughout a 20-year period between 1975 and 1996, medication compliance for antipsychotics, antidepressants and agents used in the therapy of physical ailments was estimated at $58 \%, 65 \%$ and $76 \%$, respectively (Cramer and Rosenheck 1998). Mean rate of medication non-compliance in schizophrenia identified in a systematic review of 39 studies was $41 \%$. However, when the analysis was limited solely to five methodologically flawless studies, the proportion of patients who took less than $75 \%$ of prescribed medications had increased up to 50\% (Lacro et al. 2002). Lack of compliance with antipsychotic treatment results in exacerbation of symptoms, and is associated with worse prognosis and increased demand for inpatient and acute outpatient healthcare services (Wyatt 1991; Lieberman et al. 1998; Olfson et al. 2000).

Lack of treatment adherence was shown to be associated with a worse insight, negative attitude or subjective response to pharmacotherapy, past history of non-compliance, substance abuse, shorter duration of underlying illness, inadequate discharge planning or aftercare environment, and poor therapeutic alliance (Perkins 2002). Other predictors of non-adherence identified in some, albeit not all, studies dealing with the problem in question, were age, sex, ethnicity, marital status, education level, neurocognitive impairment, intensity of psychotic symptoms, medication type and route of its administration, severity of side-effects, use of drugs at higher antipsychotic doses, presence of mood symptoms, and family involvement. However, these are patients' beliefs about their illness and potential benefits of a given treatment, its subjectively assessed side-effects (among them extrapyramidal side-effects), as well as neuroleptic dysphoria, akathisia, sexual dysfunction and weight gain, which are particularly important for medication compliance (Holzinger et al. 2002). Also a good relationship with the physician in charge is considered an important determinant of treatment adherence (Zolnierek and Dimatteo 2009).

There is no universal definition of religiosity and spirituality. Koenig et al. (2012) define spirituality as distinguished from humanism, values, morals, and mental health, by its connection to which is sacred, the transcendent' and that religion 'involves beliefs, practices, and rituals related to the transcendent, where the transcendent is God'. Huguelet in his book Religion and Spirituality in Psychiatry used the term religion to indicate specific behavioral, social, doctrinal, and denominational characteristics (Huguelet and Harold 2009). Religious and spiritual factors may play an important role in determining medication compliance in mental illness. However, systematic assessment of available evidence in this matter is needed. The aim of this paper is to review published evidence documenting a relationship between religion/spirituality (R/S) and treatment adherence in mental illness, in particular in schizophrenia, depression, and substance abuse. We summarized, categorized and defined the role of religious beliefs as a factor improving medication compliance in these major psychiatric conditions.

\section{Methods}

This study is a systematic review of published evidence regarding the influence of R/S on treatment adherence in mental illness following PRISMA (Preferred Reporting Items for Systematic reviews and Meta-Analyses) guidelines for search strategy and data collection process. The study was conducted between January 2016 and May 2016, and then its results were updated in April 2017.

\subsection{Eligibility Criteria}

Published observational and experimental studies were eligible for the review if they explored the association between R/S and outcomes in three mental illnesses: depression, anxiety and addiction. $\mathrm{R} / \mathrm{S}$ were defined as a non-medical process or message aimed at improvement of patient's status and framed by the themes of spiritual relevance. 
The search was limited to articles in English published till April 2017 and searched during period specified above.

\subsection{Search Strategies}

Original research papers and review articles identified using PubMed.

The search included the following medical subject headings: religion, spirituality combined with medication adherence, compliance/noncompliance and schizophrenia, depression, psychosis, anxiety, phobia, dissociative disorders, addiction.

Two researchers (PZ and MW) reviewed titles and abstracts of all identified articles independently, to exclude those in which R/S were not analyzed in the context of treatment adherence in mental illness, as well as to eliminate off-topic and duplicate papers.

Publications were identified as eligible for the review if based on their abstract they could be classified as (1) observational studies, addressing spirituality or religion as the determinants of treatment adherence, or (2) non-randomized or randomized studies testing the effect(s) of a given intervention on the adherence, or (3) qualitative articles, such as editorials or review papers.

Separate search strategy was used to identify other potential sources of evidence, such as textbooks and systematic reviews analyzing treatment adherence or spirituality in mental illness (Koenig et al. 2012; Masand et al. 2009; Pargament and Lomax 2013; Gonçalves et al. 2015; Van Rensburg et al. 2013).

\subsection{Data Items}

The lists of items extracted from each eligible publication included (1) clinical diagnosis, (2) sample size, (3) type of intervention or exposure, (4) outcome measures, and (5) results of the intervention. The results were analyzed as a qualitative variable, i.e., improvement of adherence or lack thereof.

\subsection{Risk of Bias}

Due to the nature of the R/S intervention and influencing variable adopted, the risk of selection bias in our review is high. A known threat to the validity of meta-analysis is publication bias, which occurs when studies with statistically significant or clinically favourable results are more likely to be published than studies with non-significant or unfavourable results. There has also been the suggestion that the potential for publication bias is greater for observational studies. Reviewer selection bias could also occur when reviewers search for studies based on specific exposure variable from a subset of existing studies through secondary search and selection takes place with knowledge of individual study results. Caution should be exercised when combining and reporting systematic reviews of observational and experimental studies. It is commonly accepted that observational studies are prone to greater degree of bias than experimental studies. There were few non-randomised studies in our review that used any method of adjustment. Some authors questions whether meta-analytic techniques can be applied to epidemiological studies at all. We did not use any methods that detect publication bias as we were unable to extract any common measure of treatment effect (adherence summary measures). Additionally within specific therapeutic area there were singular studies found (depression and anxiety). Therefore some PRISMA items requiring study estimates were not reported here. We chose to evaluate the risk of bias of each study indicating only the study design and number of participants. After data extraction, authors of this review determined that the studies were too heterogeneous to be quantitatively synthesised. We decided to show only the direction of potential association between the outcome and R/S variable instead of any specific summary measures.

\section{Results}

A total of 66 eligible abstracts were identified during PubMed search (see flowchart; Figure 1).

During the first stage of screening, abstracts were grouped according to the following outcomes of interest: (1) religiosity or spirituality as an intervention or co-variate, and (2) treatment adherence or 
medication compliance. This enabled us to exclude 31 articles that did not satisfy the inclusion criteria of this review.

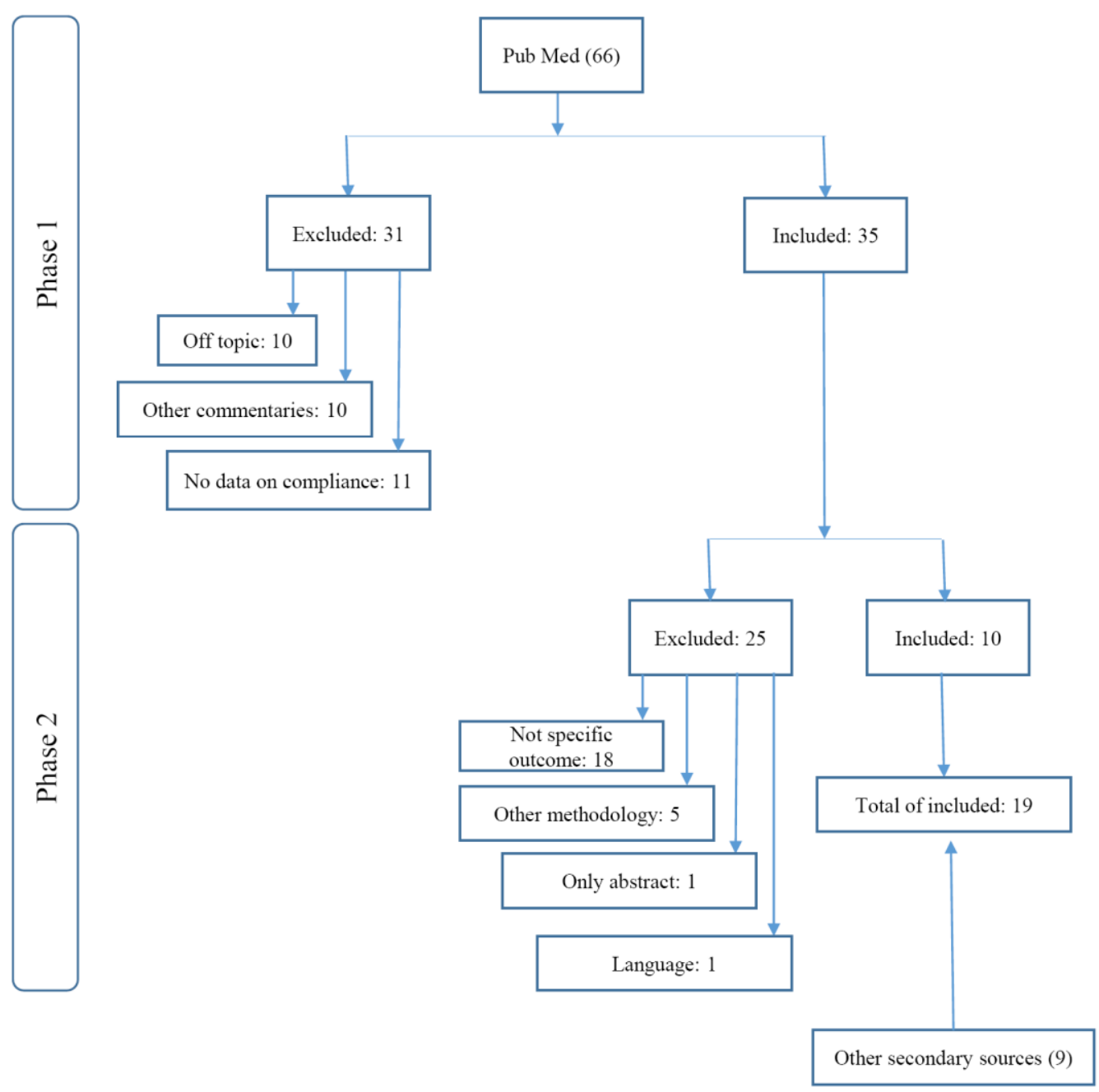

Figure 1. Flowchart of the selected studies.

The second, outcome-specific stage of screening included 35 potentially relevant papers that addressed medication compliance and R/S. A total of 10 full-text original papers and one review article were eventually identified as eligible for the review. Other 25 articles were excluded since they did not refer to the diseases of interest or medication compliance, presented psychiatric conditions that were not included in our search strategies (e.g., eating disorders), described research methodology, lacked abstract, or were not published in English.

Additional eight eligible studies were identified based on cross-reference check of review papers and books on spirituality. Therefore, a total of 18 original articles were eventually analyzed, along with one review paper referring to previous studies of treatment adherence and attendance (Zivin and Kales 2008).

\subsection{Characteristics of Studies}

General characteristics of identified studies, stratified according to the underlying mental illness, are summarized in Table 1. The studies included a total of 3449 patients with one of the diseases of interest, among them 132 individuals with depression, 125 with subclinical anxiety, 945 with schizophrenia, and 2777 with addictions. 
Table 1. Characteristics of studies included in the review.

\begin{tabular}{|c|c|c|c|c|c|c|}
\hline Mental Illness & Study & $\mathrm{N}$ of pts & Study Design & Tx/ Exposure & Outcome & Effect \\
\hline Depression & Koenig 2015 & 132 & $\mathrm{RCT}^{*}$ & $\begin{array}{l}\text { religiously integrated cognitive } \\
\text { behavioral therapy }\end{array}$ & adherence & no association \\
\hline Anxiety & Rosmarin 2010 & 125 & $\begin{array}{c}\text { randomized } \\
\text { controlled evaluation }\end{array}$ & spiritually integrated treatment & $\begin{array}{l}\text { perceptions of treatment, } \\
\text { treatment completion }\end{array}$ & positive \\
\hline \multirow{8}{*}{ Schizophrenia } & Huguelet 2011 & 78 & $\mathrm{RCT}$ & $\begin{array}{l}\text { traditional treatment and a religious } \\
\text { and spiritual assessment }\end{array}$ & treatment compliance & $\begin{array}{l}\text { no association, } \\
\text { better attendance }\end{array}$ \\
\hline & Huguelet 2006 & 100 & survey & religious beliefs & Synergy with psychiatric care & no association \\
\hline & Caqueo-Urízar A 2015 & 253 & survey & $\begin{array}{c}\text { religious beliefs about causes } \\
\text { of schizophrenia }\end{array}$ & medication attitudes & negative \\
\hline & Mohr 2012 & 276 & survey & religious coping & $\begin{array}{l}\text { compatibility with } \\
\text { psychiatric treatment }\end{array}$ & positive \\
\hline & McCann 2008 & 81 & survey & religious beliefs/activities & neuroleptic taking & no association \\
\hline & Kirov 1998 & 52 & survey & religious faith after psychosis & compliance & positive \\
\hline & Borras 2007 & 103 & survey & religious and spiritual activities & blood level of the drug & negative \\
\hline & D'Souza 2004 & 2 & case series & SACBT (spirituality augmented) & treatment collaboration/relapse rate & positive \\
\hline \multirow{8}{*}{ Addiction } & Krentzman 2013 & 364 & cohort & spirituality dimensions & AA participation & positive \\
\hline & Kelly 2011 & 1726 & cohort & spirituality religiousness & AA attendance & positive \\
\hline & Arnold 2002 & 68 & survey & spirituality & expectations/perceptions & positive \\
\hline & Brown 2001 & 71 & cohort & measures of religiosity & attendance & no association \\
\hline & Stahler 2007 & 18 & RCT & Church communities & treatment retention & positive \\
\hline & Chi 2009 & 357 & cohort & 12-step/religiosity co-variate & abstinence & positive \\
\hline & Margolin 2006 & 72 & controlled study & 3-S (Spiritual Self Schema therapy) & motivation for HIV prevention & positive \\
\hline & Christo 1995 & 101 & cohort & spiritual beliefs & $\begin{array}{l}\text { NA (narcotics } \\
\text { anonymous) attendance }\end{array}$ & no association \\
\hline Mental Illness & Foulks 1986 & 60 & cohort & patients' beliefs & compliance & no association \\
\hline
\end{tabular}

${ }^{*}$ RCT- Randomised Clinical Trial. 
When stratified according to study design, the list eligible publications included 4 randomized studies, 1 controlled study, 4 cohort studies, 7 surveys, and 1 case series.

\subsection{Interventions and/or Outcome Measures}

Few studies were R/S intervention studies, and majority of papers address R/S as an influencing variable. The subset of experimental studies included a clinical trial in depression, randomized controlled evaluation in anxiety, randomized clinical trial in schizophrenia, community trial in cocaine addiction, and controlled study in drug users, one each.

The list of evaluated interventions included religiously integrated cognitive behavioral therapy that used patient's religious beliefs to identify and replace unhelpful thoughts and behaviors, in order to reduce depressive symptoms. Other spiritual approaches to intervention were spiritually integrated treatment including reading inspiring stories and excerpts from Jewish religious literature (study of anxiety in a Jewish community) and spiritual assessment by a psychiatrist followed by guidance and advice from a psychologist of religion (in schizophrenia patients). One study used spirituality-focused intervention based on a Buddhist framework. In another study, Bridges intervention consisting of interactions between church community and local activists or mentors was evaluated in a group of cocaine-dependent black women.

Non-experimental studies dealt with various measures or dimensions of spirituality/religiosity. Some studies involved specific validated questionnaires ("Multidimensional Measurement of Religiousness or Spirituality for Use in Health Research", "Religious Coping Index", "Spiritual Beliefs Questionnaire") or ad hoc semi-structured interviews developed by the authors. In a study of alcohol dependence, spirituality/religiousness were assessed with Religious Background and Behavior instrument. Other studies used some simple measures of spirituality/religiousness, such as the involvement in religious/spiritual activities or spiritual beliefs regarding the causes of mental illness ("magical-religious causes").

\subsection{Outcomes and Associations}

The list of eligible studies included only one randomized trial analyzing treatment adherence in depression. In this study, more religious patients presented with better adherence and had better treatment outcomes. Religiosity was shown to interact with treatment type: religiously-integrated CBT (RBCT) turned out to be slightly more effective in religious participants; also adherence to RCBT in this group was somehow better than in other study subjects ( $85.7 \%$ vs. $65.9 \%, p=0.10)$ (Koenig et al. 2015). Importantly, better adherence was not related to the intervention, but resulted from baseline intergroup differences in religiosity levels.

In a single randomized study of patients with anxiety, individuals subjected to spirituality-integrated treatment (SIT) reported higher levels of belief in treatment credibility, had greater expectations from treatment, and were more likely to complete the therapy than the controls offered progressive muscle relaxation (PMR) (Rosmarin et al. 2010).

Only few eligible studies analyzed the effects of religion on medication compliance in schizophrenia. Noticeably, religious beliefs either exerted no effect or even negatively affected treatment adherence in patients with this condition.

In one clinical trial, schizophrenia patients were subjected to a spiritual assessment conducted by a psychiatrist, followed by a guidance and advice from a psychologist of religion. Although three months later, medication compliance and satisfaction with care in this group were similar as in the controls, the intervention contributed to significantly better appointment attendance during the follow-up period (Huguelet et al. 2011).

The authors of six surveys analyzed religious determinants of medication compliance in schizophrenia patients. Only few among one hundred individuals with this condition considered religious practice to be incompatible with treatment (Huguelet et al. 2006). However, this study did not provide sufficient evidence to support the role or religious beliefs as a determinant of better adherence. 
It showed only the neutral attitude among religious patients towards medication use. In only one study, medication compliance was determined not only based on the interview, but also through a systematic monitoring of drug levels in patients' blood. The study showed that religious representations of illness were more prominent in non-adherent subjects (Borras et al. 2007). Also a survey of 276 outpatients with a DSM-IV diagnosis of schizophrenia or schizoaffective disorder demonstrated that religion may sometimes interfere with psychiatric treatment (Mohr et al. 2012).

Another study analyzed opinions on the causes of schizophrenia in 253 patients with this condition and in their caregivers. Stronger magical-religious beliefs turned out to be associated with higher incidence of positive symptoms and less favorable attitudes to pharmacotherapy. Patients' belief system turned out to be a significant predictor of medication attitude. Furthermore, a significant correlation was found between the medication attitudes and PANSS scores, which points to a likely link between treatment compliance and symptom severity (Caqueo-Urízar et al. 2015). However, a small study of 81 patients with schizophrenia did not demonstrate an association between the level of involvement in religious or spiritual practices and medication compliance (McCann et al. 2008). In another study, $61 \%$ out of 52 patients used religion to cope with their psychotic illness. Importantly, these patients had a better insight into their disease, and were more compliant with antipsychotic therapy (Kirov et al. 1998).

Finally, according to one published case report, a 56-year-old woman with psychotic depression re-involved in her life and showed complete treatment adherence after participation in a spiritually augmented cognitive behavioral therapy (SACBT) (D'Souza and Rodrigo 2004).

A better quality evidence originates from the research on addictions, as these studies included substantially larger number of participants, and typically (in 7 out of 8 studies) had a longitudinal design. In a controlled study analyzing the effects of spirituality-focused intervention in drug users, better treatment compliance was associated with greater involvement in spiritual practices and stronger motivation to prevent HIV infection. Moreover, participation in Spiritual Self Schema (3-S) therapy and stronger motivation to prevent HIV infection turned out to be associated with lower prevalence of HIV-risk behaviors (Margolin et al. 2006).

In the largest of analyzed studies, involving a total of 1726 subjects with alcohol use disorders, participation in Alcoholic Anonymous (AA) meetings exerted a significant effect on future drinking outcomes, which was partially explained by an association between the involvement in AA movement and higher levels of spirituality/religiousness. This study has controlled confounding variables and found that "attending AA was associated with increases in spiritual practices" and that alcohol outcomes were "partially mediated by increases in spirituality". This implies that spirituality/religiousness may serve as a mechanism of AA-related change and contribute to better attendance in AA meetings (Kelly et al. 2011). In another 18-month longitudinal study of 364 alcohol addicts, spiritual orientation was identified as an important aspect of recovery and a determinant of better treatment adherence (Krentzman et al. 2013). Further, a small preliminary study of 18 cocaine-dependent black women assigned randomly to Bridges treatment or standard residential therapy alone, demonstrated that the former approach was associated with significantly better treatment retention at six months ( $75 \% \mathrm{vs}$. $20 \%$, as assessed by urinalysis) (Stahler et al. 2007).

The results of a study conducted among 357 adolescents with chemical dependence imply that religious service attendance might exert a mediating effect on the relationship between post-treatment 12-Step affiliation (TSA) and 3-year outcomes (Chi et al. 2009). However, frequent religious service attendance was shown to mediate solely the relationship between TSA and drug abstinence, and exerted no effect on the association between TSA and alcohol abstinence.

In a small study of 71 patients participating in Narcotics Anonymous and/or AA meetings, frequent attenders did not differ from infrequent attenders and non-attenders in terms of their religiosity measures (Brown et al. 2001). However, a study of 101 drug users identified spiritual beliefs as a predictor of regular participation in Narcotics Anonymous (NA) meetings (Christo and Franey 1995). In another, smaller study, the vast majority of $47 \mathrm{HIV}$-positive drug users declared their interest in 
receiving spirituality-focused treatment, and believed that combined with medical recommendations, this form of intervention may help them to reduce craving and HIV-risk behaviors, as well as to promote hopefulness (Arnold et al. 2002).

The review paper included in the analysis referred to a study analyzing the role of patients' beliefs as a determinant of partial adherence to antipsychotic medications (Masand et al. 2009). Unfortunately, authors of this study did not specify the exact psychiatric diagnosis established in their participants, other than mentioning that they examined the subjects "treated in the outpatient psychiatric clinic". Nevertheless, the study did not show an association between patients' beliefs and medication compliance (Foulks et al. 1986).

\section{Discussion}

This review showed that published evidence documenting the effects of religiosity on medication compliance in mental illness is quite limited.

The effects of religious interventions or religious exposure on treatment adherence vary depending on an underlying mental illness. While religious beliefs were associated with poor compliance in schizophrenia patients, spiritual orientation turned out to be an important aspect of recovery from addiction and a determinant of better treatment adherence in individuals with substance dependence. Better medication compliance was also observed in more religious patients with depression or anxiety, but available evidence is too limited for any ultimate conclusions in this matter.

Published evidence suggests that religious and spiritual interventions (RSI) may alleviate stress, alcoholism and depression. RCTs documented additional beneficial effects of RSI, among them attenuation of clinical symptoms (Gonçalves et al. 2015). More religious persons seem to be more likely to involve in disease-screening practices and comply better with prescribed medical treatments (Koenig et al. 2012). However, our review suggests that the same does not apply to individuals with mental illness.

\subsection{Treatment Adherence in Schizophrenia}

The lack of association or even an inverse relationship between religiosity and medication compliance seem to be particularly evident in schizophrenia patients. This points to an important role of insight in the context of mental illness. Relative lack of the insight may contribute to worse adherence (Mutsatsa et al. 2003). The term "insight" refers to patient's ability to recognize that his/her symptoms are associated with a mental illness and as such require an appropriate treatment. Lack of the insight is known to be associated with impaired cognitive function, and to predict poor medication compliance. This may be particularly challenging in psychotic patients in whom lack of the insight may interfere with both treatment and religious attitudes. Patients' opinion about the etiology of their mental disease usually reflects their general worldview, and not infrequently is also influenced by religious beliefs. Some more religious patients may accept a personalistic explanation of their illness, and believe that either its etiology or treatment extend beyond a natural world and involve some supernatural forces. Lack of the insight may dramatically alter medication compliance in patients with psychotic symptoms. Religion is often entangled in neurotic and psychotic disorders, and the content of delusions may be related to one's religious beliefs. Delusions may help to cope with some negative life events; however, they are often referred to as false beliefs, and probably do not produce a favorable effect in a longer perspective. Some proportion of people may experience psychotic symptoms, including auditory hallucinations. Such persons, especially more religious subjects, will probably try to make sense of these experiences; however, such religious delusions may negatively influence medication compliance.

\subsection{Treatment Adherence in Addiction}

The vast majority of identified studies of addictions demonstrated beneficial effects of religion and spirituality on treatment adherence. Most treatment protocols were based on 12-step programs and participation in AA meetings, i.e., therapeutic modalities in which spiritual elements constitute 
an integral component. Application of religious and spiritual issues to the therapy of addictions is relatively easy, owing moral aspects of substance abuse and important role of patient's will power as a determinant of persistent abstinence. Religion provides arguments against substance abuse, and gives motivation to involve in other activities than the addiction. Participants of the studies included in this review did not suffer from other mental comorbidities, and their cognitive skills and insight enabled them to rationally self-evaluate their situation and to continue the therapy. Therefore, inclusion of religious issues in therapeutic programs produced a beneficial effect in form of treatment retention.

\subsection{Treatment Adherence in Depression and Anxiety}

Only a limited number of studies dealing with depression and anxiety-related disorders satisfied criteria of this review. Although many previous studies analyzed the effects of spirituality and religiousness on treatment outcomes in depression, only one centered around a clearly defined level of treatment adherence (Koenig et al. 2015). This randomized study demonstrated that beneficial effect of patient's religiosity is independent of a religious intervention; more religious patients benefited more form the therapy, showed higher levels of treatment adherence and better treatment retention. However, unless adjusted for patient's religiosity, treatment adherence levels in individuals subjected to religious (RCBT) and conventional therapy (CCBT) were essentially the same. Similar to depression, we have identified only one randomized study analyzing the effect of Internet-based therapy in individuals with subclinical anxiety. The study showed that the proportion of patients who completed a religious therapy was significantly higher than the percentage of subjects who fully adhered to a conventional treatment (Rosmarin et al. 2010).

\subsection{Quality of Evidence}

Published evidence documenting beneficial effects of religiosity on treatment adherence is quite limited. Heterogeneity of patient populations and limitations in the study types made this review particularly challenging. Among all 19 eligible studies, there were only four in which the subjects were randomized to intervention. Experimental studies had a pilot character, included a small number of subjects (between 18 and 132), and were aimed at preliminary assessment of intervention outcomes. Randomized studies in schizophrenia and depression demonstrated that religiosity/spirituality had no effect on treatment adherence. We may conclude, then, if treatment compliance in schizophrenia and depression is related to religiosity and spirituality, it can't be influenced through intervention. While a few studies analyzed medication compliance, only one monitored blood level of the drug (Huguelet et al. 2011; Mohr et al. 2012; McCann et al. 2008; Borras et al. 2007). All these studies included patients with schizophrenia, i.e., condition in which medication compliance is of vital importance. In the study which analyzed blood level of the drug, an inverse relationship was found between religiosity and medication compliance (Borras et al. 2007). Studies of patients with addictions, including between 357 and 1,726 subjects, were the largest sources of evidence for this review (Kelly et al. 2011; Krentzman et al. 2013; Lin et al. 2014). These studies were based on a 12-step program for recovery from addiction, including spiritual elements; participation in this form of intervention apparently stimulated involvement of patients in religious activities. This with no doubt hindered the analysis of a temporal relationship between religiosity and treatment outcomes. It is unclear if participation in AA therapy promoted religiousness, or it was religiousness which facilitated achieving desired therapeutic effects. Probably, both these mechanisms may be involved (Galanter et al. 2007).

\subsection{Limitations}

Another important limitation of this study is heterogeneity of S/R measures. Whilst religiosity is relatively straight-forward to measure, spirituality is more difficult. The question of whether spirituality can be subjected to scientific research methodologies should be raised here. We did not differentiate spirituality from religion in this review. There are differences between attitudes and convictions on the one hand (belief in God, centrality, etc.) and engagement in S/R practices (church attendance, praying, 
meditation, etc.) on the other. Spiritual interventions can utilize the power of prayer and meditation, coping and transcendence, while religious approaches include specific traditions of Christians and Jews, conducted in pastoral services and therapeutic models. There are some aspects in philosophy and values of AA meetings that are not necessarily "spiritual". Looking for the strength to remain abstinent leads to healthier way of life that shares some common values with $\mathrm{R} / \mathrm{S}$ but it is not spirituality itself.

\section{Conclusions}

This systematic review demonstrated that religiosity may influence treatment adherence in mental illness. With no doubt, inclusion of religious and spiritual components produces the most beneficial effects in the treatment of addictions. However, involvement of religiosity does not necessarily stimulate treatment adherence in patients with psychotic disorders and schizophrenia, and may even affect it negatively in the case of individuals with delusional interpretation of their illness etiology. There is no good quality evidence that religion may influence better compliance through intervention. Inclusion of religiosity and spirituality may be however necessary in the case of some patients with depression and anxiety, as it stimulates adherence, which eventually contributes to better treatment outcomes. These findings should motivate therapists and psychiatrists to routinely consider religiosity in treatment plans for their patients.

Acknowledgments: This work was supported by the Medical University of Gdansk (grant no.ST-20).

Author Contributions: Pawel Zagozdzon was responsible for the conception and design of the work, data analysis, interpretation and writing. Both authors Pawel Zagozdzon and Magdalena Wrotkowska contributed equally to literature search and data collection. Magdalena Wrotkowska was responsible for figures and bibliography for the article.

Conflicts of Interest: Pawel Zagozdzon and Magdalena Wrotkowska declared that there were no conflicts of interest in relation to the subject of this study.

\section{References}

Arnold, Ruth M., S. Kelly Avants, Arthur Margolin, and David Marcotte. 2002. Patient Attitudes Concerning the Inclusion of Spirituality into Addiction Treatment. Journal of Substance Abuse Treatment 23: 319-26. [CrossRef]

Borras, Laurence, S. Mohr, P.-Y. Brandt, C. Gilliéron, A. Eytan, and P. Huguelet. 2007. Religious Beliefs in Schizophrenia: Their Relevance for Adherence to Treatment. Schizophrenia Bulletin 33: 1238-46. [CrossRef] [PubMed]

Brown, Barry S., Kevin E. O'Grady, Eugene V. Farrell, Ilene S. Flechner, and David N. Nurco. 2001. Factors Associated with Frequency of 12-Step Attendance by Drug Abuse Clients. The American Journal of Drug and Alcohol Abuse 27: 147-60. [CrossRef] [PubMed]

Caqueo-Urízar, Alejandra, Laurent Boyer, Karine Baumstarck, and Stephen E. Gilman. 2015. The Relationships between Patients' and Caregivers' Beliefs about the Causes of Schizophrenia and Clinical Outcomes in Latin American Countries. Psychiatry Research 229: 440-46. [CrossRef] [PubMed]

Chi, Felicia W., Lee A. Kaskutas, Stacy Sterling, Cynthia I. Campbell, and Constance Weisner. 2009. Twelve-Step Affiliation and 3-Year Substance Use Outcomes among Adolescents: Social Support and Religious Service Attendance as Potential Mediators. Addiction (Abingdon, England) 104: 927-39. [CrossRef] [PubMed]

Christo, George, and Christine Franey. 1995. Drug Users' Spiritual Beliefs, Locus of Control and the Disease Concept in Relation to Narcotics Anonymous Attendance and Six-Month Outcomes. Drug and Alcohol Dependence 38: 51-56. [CrossRef]

Cramer, Joyce A., and Robert Rosenheck. 1998. Compliance with Medication Regimens for Mental and Physical Disorders. Psychiatric Services (Washington, D.C.) 49: 196-201. [CrossRef] [PubMed]

D'Souza, Russell F., and Angelo Rodrigo. 2004. Spiritually Augmented Cognitive Behavioural Therapy. Australasian Psychiatry: Bulletin of Royal Australian and New Zealand College of Psychiatrists 12: 148-52. [CrossRef] [PubMed]

Foulks, Edward F., J. B. Persons, and R. L. Merkel. 1986. The Effect of Patients' Beliefs about Their Illnesses on Compliance in Psychotherapy. The American Journal of Psychiatry 143: 340-44. [CrossRef] [PubMed] 
Galanter, Marc, Helen Dermatis, Gregory Bunt, Caroline Williams, Manuel Trujillo, and Paul Steinke. 2007. Assessment of Spirituality and Its Relevance to Addiction Treatment. Journal of Substance Abuse Treatment 33: 257-64. [CrossRef] [PubMed]

Gonçalves, Juliane P. B., G. Lucchetti, P. R. Menezes, and H. Vallada. 2015. Religious and Spiritual Interventions in Mental Health Care: A Systematic Review and Meta-Analysis of Randomized Controlled Clinical Trials. Psychological Medicine 45: 2937-49. [CrossRef] [PubMed]

Haynes, R. Brian, David L. Sackett, D. Wayne Taylor, R. S. Roberts, and A. L. Johnson. 1977. Manipulation of the Therapeutic Regimen to Improve Compliance: Conceptions and Misconceptions. Clinical Pharmacology and Therapeutics 22: 125-30. [CrossRef] [PubMed]

Holzinger, Anita, Watter Loffler, Peter Muller, Stefan Priebe, and Matthias C. Angermeyer. 2002. Subjective Illness Theory and Antipsychotic Medication Compliance by Patients with Schizophrenia. The Journal of Nervous and Mental Disease 190: 597-603. [CrossRef] [PubMed]

Huguelet, Philippe, and Koenig Harold. 2009. Introduction: Key Concepts. In Religion and Spirituality in Psychiatry, 1st ed. Cambridge: Cambridge University Press, pp. 1-4.

Huguelet, Philippe, Sylvia Mohr, Carine Betrisey, Laurence Borras, Christiane Gillieron, Adham Mancini Marie, Isabelle Rieben, Nader Perroud, and Pierre-Yves Brandt. 2011. A Randomized Trial of Spiritual Assessment of Outpatients with Schizophrenia: Patients' and Clinicians' Experience. Psychiatric Services (Washington, D.C.) 62: 79-86. [CrossRef] [PubMed]

Huguelet, Philippe, Sylvia Mohr, Laurence Borras, Christiane Gillieron, and Pierre-Yves Brandt. 2006. Spirituality and Religious Practices among Outpatients with Schizophrenia and Their Clinicians. Psychiatric Services (Washington, D.C.) 57: 366-72. [CrossRef] [PubMed]

Van Rensburg, ABR Janse, C. P. H. Myburgh, C. P. Szabo, and M. Poggenpoel. 2013. The Role of Spirituality in Specialist Psychiatry: A Review of the Medical Literature. African Journal of Psychiatry 16: 247-55. [CrossRef]

Kelly, John F., Robert L. Stout, Molly Magill, J. Scott Tonigan, and Maria E. Pagano. 2011. Spirituality in Recovery: A Lagged Mediational Analysis of Alcoholics Anonymous' Principal Theoretical Mechanism of Behavior Change. Alcoholism, Clinical and Experimental Research 35: 454-63. [CrossRef] [PubMed]

Kirov, George, R. Kemp, K. Kirov, and A. S. David. 1998. Religious Faith after Psychotic Illness. Psychopathology 31: 234-45. [CrossRef] [PubMed]

Koenig, Harold G., Michelle J. Pearce, Bruce Nelson, Sally F. Shaw, Clive J. Robins, Noha S. Daher, Harvey Jay Cohen, L. S. Berk, D. L. Bellinger, K. I. Pargament, and et al. 2015. Religious vs. Conventional Cognitive Behavioral Therapy for Major Depression in Persons with Chronic Medical Illness: A Pilot Randomized Trial. The Journal of Nervous and Mental Disease 203: 243-51. [CrossRef] [PubMed]

Koenig, Harold, Dana King, and Verna B. Carson. 2012. Psychological, Social, and Behavioral Pathways. In Handbook of Religion and Health, 2nd ed. Oxford and New York: Oxford University Press, pp. 579-99.

Krentzman, Amy R., James A. Cranford, and Elizabeth A. R. Robinson. 2013. Multiple Dimensions of Spirituality in Recovery: A Lagged Mediational Analysis of Alcoholics Anonymous' Principal Theoretical Mechanism of Behavior Change. Substance Abuse 34: 20-32. [CrossRef] [PubMed]

Lacro, Jonathan P., Laura B. Dunn, Christian R. Dolder, Susan G. Leckband, and Dilip V. Jeste. 2002. Prevalence of and Risk Factors for Medication Nonadherence in Patients with Schizophrenia: A Comprehensive Review of Recent Literature. The Journal of Clinical Psychiatry 63: 892-909. [CrossRef] [PubMed]

Lieberman, Jeffrey A., Brian Sheitman, Miranda Chakos, Delbert Robinson, Nina Schooler, and Sam Keith. 1998. The Development of Treatment Resistance in Patients with Schizophrenia: A Clinical and Pathophysiologic Perspective. Journal of Clinical Psychopharmacology 18: 20S-4S. [CrossRef]

Lin, Shuai-Ting, Cheng-Chung Chen, Hin-Yeung Tsang, Chee-Siong Lee, Pinchen Yang, Kai-Da Cheng, Dian-Jeng Li, Chin-Jen Wang, Yung-Chi Hsieh, and Wei-Cheng Yang. 2014. Association between Antipsychotic Use and Risk of Acute Myocardial Infarction: A Nationwide Case-Crossover Study. Circulation 130: 235-43. [CrossRef] [PubMed]

Margolin, Arthur, Mark Beitel, Zev Schuman-Olivier, and S. Kelly Avants. 2006. A Controlled Study of a Spirituality-Focused Intervention for Increasing Motivation for HIV Prevention among Drug Users. AIDS Education and Prevention: Official Publication of the International Society for AIDS Education 18: 311-22. [CrossRef] [PubMed] 
Masand, Prakash S., Miquel Roca, Martin S. Turner, and John M. Kane. 2009. Partial Adherence to Antipsychotic Medication Impacts the Course of Illness in Patients with Schizophrenia: A Review. Primary Care Companion to the Journal of Clinical Psychiatry 11: 147-54. [CrossRef] [PubMed]

McCann, Terence V., Cecil Deans, Eileen Clark, and Sai Lu. 2008. A Comparative Study of Antipsychotic Medication Taking in People with Schizophrenia. International Journal of Mental Health Nursing 17: 428-38. [CrossRef] [PubMed]

Mohr, Sylvia, Laurence Borras, Jennifer Nolan, Christiane Gillieron, Pierre-Yves Brandt, Ariel Eytan, Claude Leclerc, Nader Perroud, Kathryn Whetten, and Carl Pieper. 2012. Spirituality and Religion in Outpatients with Schizophrenia: A Multi-Site Comparative Study of Switzerland, Canada, and the United States. International Journal of Psychiatry in Medicine 44: 29-52. [CrossRef] [PubMed]

Mutsatsa, Stan H., E. M. Joyce, S. B. Hutton, E. Webb, H. Gibbins, S. Paul, and T. R. E. Barnes. 2003. Clinical Correlates of Early Medication Adherence: West London First Episode Schizophrenia Study. Acta Psychiatrica Scandinavica 108: 439-46. [CrossRef] [PubMed]

Olfson, Mark, David Mechanic, Stephen Hansell, Carol A. Boyer, James Walkup, and Peter J. Weiden. 2000. Predicting Medication Noncompliance After Hospital Discharge Among Patients With Schizophrenia. Psychiatric Services 51: 216-22. [CrossRef] [PubMed]

O Sarri, Katerina, Siobhan Higgins, and Anthony G. Kafatos. 2005. Are Religions "Healthy"? A Review on Religious Recommendations on Diet and Lifestyle. Human Ecology Special Issue 14: 7-20.

Pargament, Kenneth I., and James W. Lomax. 2013. Understanding and Addressing Religion among People with Mental Illness. World Psychiatry: Official Journal of the World Psychiatric Association (WPA) 12: 26-32. [CrossRef] [PubMed]

Perkins, D. O. 2002. Predictors of noncompliance in patients with schizophrenia. Journal of Clinical Psychiatry 63: 1121-28.

Rosmarin, David H., Kenneth I. Pargament, Steven Pirutinsky, and Annette Mahoney. 2010. A Randomized Controlled Evaluation of a Spiritually Integrated Treatment for Subclinical Anxiety in the Jewish Community, Delivered via the Internet. Journal of Anxiety Disorders 24: 799-808. [CrossRef] [PubMed]

Stahler, Gerald J., Kimberly C. Kirby, and MaryLouise E. Kerwin. 2007. A Faith-Based Intervention for Cocaine-Dependent Black Women. Journal of Psychoactive Drugs 39: 183-90. [CrossRef] [PubMed]

Wyatt, Richard Jed. 1991. Neuroleptics and the Natural Course of Schizophrenia. Schizophrenia Bulletin 17: 325-51. [CrossRef] [PubMed]

Zivin, Kara, and Helen C. Kales. 2008. Adherence to Depression Treatment in Older Adults: A Narrative Review. Drugs \& Aging 25: 559-71.

Zolnierek, Kelly B. Haskard, and M. Robin Dimatteo. 2009. Physician Communication and Patient Adherence to Treatment: A Meta-Analysis. Medical Care 47: 826-34. [CrossRef] [PubMed] 